\title{
Creep-fatigue interaction in heat resistant austenitic alloys
}

\author{
Hugo Wärner ${ }^{1, *}$, Mattias Calmunger ${ }^{1}$, Guocai Chai $^{1,2}$ and Johan Moverare ${ }^{1}$ \\ ${ }^{1}$ Department of Management and Engineering, Linköping University, 58183 Linköping, Sweden \\ ${ }^{2}$ AB Sandvik Materials Technology R\&D Center, 81181 Sandviken, Sweden
}

\begin{abstract}
This work includes an investigation of two commercial austenitic steels: UNS S21500 (Esshete 1250) and UNS S31035 (Sandvik Sanicro ${ }^{\text {TM }} 25$ ). The materials were exposed to isothermal strain controlled fatigue with load controlled dwell time at maximum strain. The testing temperature used was $700^{\circ} \mathrm{C}$ and the test cycles were performed in tension. Mechanical test data were obtained and analysed in order to define creep-fatigue damage diagrams at failure for the investigated austenitic alloys. During the given conditions, Sanicro 25 showed superior creep-fatigue life, suffered less amount of creep elongation for the same amount of strain amplitude and dwell times compared to Esshete 1250. Both alloys showed creep-fatigue interaction damage for specific test configurations.
\end{abstract}

\section{Introduction}

Rising global energy consumption and the increase in emissions of greenhouse gases (e.g. $\mathrm{CO}_{2}$ ) causing global warming, make need for more sustainable power generation $[1,2]$. This could be accomplished by increasing the efficiency of biomass-fired, biomass cofiring and coal-fired power plants, which is achieved by increasing the steam temperature and steam pressure in the boiler sections [3-5]. By increasing the steam data to advanced-ultra super critical condition (A-USC) with temperature up to $700^{\circ} \mathrm{C}$ and pressures up to $36 \mathrm{MPa}$ the efficiency can be increased to over $50 \%$ and the emission of $\mathrm{CO}_{2}$ can be reduced by up to $10 \%$ compared to conditions with steam data at $25 \mathrm{MPa}$ and $540^{\circ} \mathrm{C}$ (Super critical condition) $[4,6]$. In addition, flexible generation of power is critical to compensate for the deficiencies of renewable power generation, such as solar and wind power, and this will increase the number of start-and stop cycles $[3,7,8]$. The change in operation conditions will increase the demands on the materials in the critical components of the power plants. Both cyclic condition and extended service in a long-term high temperature environment are operation conditions that such materials must withstand. Traditionally, ferritic and austenitic stainless steels are used for critical components of power plants, but with more demanding conditions other highly alloyed austenitic stainless steels could be more suitable for long-term service [6].

These new operating conditions involves a combined accumulation of cyclic damage and creep damage originated from start-up and shut-down and extended service at increased temperature and pressure. The interaction behaviour of creep and fatigue for a material is a complex and sometimes a competing process that depend on temperature, strain rate, dwell time, chemical composition and environment. Relevant investigations of the creep and fatigue process has been conducted for the austenitic 316 stainless steel by Hales [9] and Plumbridge [10]. The investigations reported four types of interaction cases where the type of initiation damage in the microstructure depend on if fatigue, creep or both fatigue and creep is the dominant process. For highly alloyed austenitic stainless steels, this has not been fully investigated and further work are needed to verify that the demands on safety for cyclic long-term usage is fulfilled.

This paper will present results from Creep-Low Cycle Fatigue (LCF) testing with alternating strain amplitudes and dwell times. Two austenitic alloys, candidates for critical components in the power generation industry, were investigated and the mechanical response of different creep-LCF conditions were analysed in order to determine the interaction behaviour and type of initiation damage.

\section{Material and methodology}

\subsection{Austenitic alloys}

The investigations involved two commercial austenitic alloys UNS S21500 (Esshete 1250) and UNS S31035 (Sandvik Sanicro $^{\mathrm{TM}}$ 25). Before mechanical testing Sanicro 25 were solution heat treated at $1220^{\circ} \mathrm{C}$ for 10 minutes and Esshete 1250 were solution heat treated at $1100^{\circ} \mathrm{C}$ for 15 minutes. Sandvik Materials Technology $\mathrm{AB}$ (SMT) provided and heat-treated the materials. The chemical composition of the materials in $\mathrm{wt} \%$ is given in Table 1.

\subsection{Methodology}

The mechanical testing were performed using an MTS servo hydraulic testing machine equipped with an Instron 8800 control system. The strain was measured by an Instron 2632-055 extensometer and the isothermal condition, at $700^{\circ} \mathrm{C}$, was controlled by an MTS 652.01 furnace. The $\mathrm{R} \varepsilon=0$-type test cycle involved a strain

\footnotetext{
Corresponding author: hugo.warner@liu.se
} 
controlled part, dashed line in Figure 1, and a load controlled part, solid line in Figure 1. Strain ranges from
$0.5-1.0 \%$ and dwell times, $t_{d}$, from $0-1800$ seconds were

Table 1. Chemical composition (in wt $\%$ ) of the austenitic alloys.

\begin{tabular}{lccccccccccccc}
\hline Material & $\mathrm{C}$ & $\mathrm{Cr}$ & $\mathrm{Ni}$ & $\mathrm{W}$ & $\mathrm{Co}$ & $\mathrm{Cu}$ & $\mathrm{Mn}$ & $\mathrm{Nb}$ & $\mathrm{N}$ & $\mathrm{Si}$ & $\mathrm{V}$ & $\mathrm{Mo}$ & $\mathrm{Fe}$ \\
\hline Sanicro 25 & 0.1 & 22.5 & 25.0 & 3.6 & 1.5 & 3.0 & 0.5 & 0.5 & 0.23 & 0.2 & - & - & Bal. \\
Esshete1250 & 0.1 & 15 & 9.5 & - & - & - & 6.3 & 1.0 & - & 0.5 & 0.3 & 1.0 & Bal
\end{tabular}

tested. Setup and employment of the test as well as definition of plastic strain range, $\Delta \varepsilon_{p}$, stress range, $\Delta \sigma$, and total strain amplitude, $\Delta \varepsilon / 2$, were conducted according to ASTM standard E2714-3 for CreepFatigue testing [9]. The number of cycles until failure, $N_{f}$, was defined as the point at which the amplitude stress, $\Delta \sigma / 2$, decreases $10 \%$ below the tangent line constructed at the last point of zero curvature, as suggested by [11].

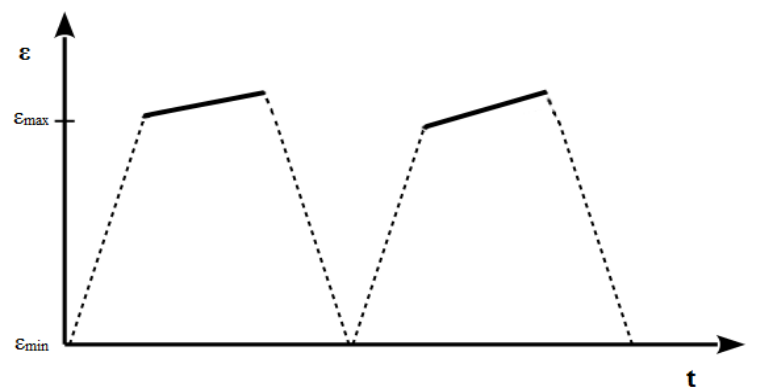

Fig. 1. Sketch of the Creep-LCF test cycle, strain $(\varepsilon)$ versus time $(\mathrm{t})$.

The creep-fatigue interaction diagrams were constructed similarly to those in "ASME boiler and pressure vessel code" [12] with the assumption that creep damage and fatigue damage may be evaluated separately and then merged to receive the total damage i.e. linear summation damage technique (Miners rule).

$$
\sum\left(\Delta t / T_{l}\right)_{k}+\sum\left(n / N_{l}\right)_{j} \leq D
$$

This is displayed in equation (1).

Where $D$ is the creep-fatigue damage factor, $\left(N_{l}\right)_{j}$ is the number of allowable cycles of type $j,\left(T_{D}\right)_{k}$ is the allowable time at stress level $k, n$ is the actual number of cycles of type $j$ and $\Delta t$ is the actual time at stress level $k$.

The performed test used for construction of the diagrams can be viewed in Table 2. Reference data for creep rupture time at different stress levels were provided by SMT [13], however, the cyclic reference data were obtained from this study.

\section{Results}

\subsection{Sanicro 25}

In the stress versus cycles to failure diagram, Figure 2, at the beginning, Sanicro 25 shows cyclic hardening followed by cyclic softening after the maximum stress and until failure, for tests with different $\Delta \varepsilon / 2$ and constant

Table 2. Test for the Creep-Fatigue interaction diagrams.

\begin{tabular}{lccc}
\hline Test $\mathrm{Nr}$ & Material & $\Delta \varepsilon / 2[\%]$ & $\mathrm{t}_{\mathrm{d}}[\mathrm{s}]$ \\
\hline 1 & Sanicro 25 & 0.25 & 0 \\
2 & Sanicro 25 & 0.25 & 300 \\
3 & Sanicro 25 & 0.375 & 600 \\
4 & Sanicro 25 & 0.25 & 600 \\
5 & Sanicro 25 & 0.25 & 1800 \\
6 & Esshete 1250 & 0.25 & 0 \\
7 & Esshete 1250 & 0.25 & 100 \\
8 & Esshete 1250 & 0.25 & 300 \\
9 & Esshete 1250 & 0.25 & 600 \\
10 & Esshete 1250 & 0.25 & 1800 \\
\hline
\end{tabular}

$t_{d}$. Also higher strain amplitude yields shorter creepfatigue life. In Figure 3 a) tests with constant $\Delta \varepsilon / 2$ and different $t_{d}$, shows that longer $t_{d}$ results in lower maximum stress and shorter creep-fatigue life. In Figure $3 \mathrm{~b}$ ), the life is calculated in total test time instead of cycles to failure and plainly, tests with longer $t_{d}$ have longer life.

The hysteresis loops in Figure 4 a) shows that with increasing number of cycles, maximum stress and elongation during $t_{d}$ also increases. Although, in the same figure it is clear that the $\Delta \varepsilon_{p}$ decreases with increasing number of cycles. Comparing a cycle at the beginning of the test with a cycle at $90 \%$ of life, the reduction of $\Delta \varepsilon_{p}$ is $14.4 \%$. At lower $\Delta \varepsilon / 2$, displayed in Figure $4 \mathrm{~b}$ ), Sanicro 25 show an earlier decrease of maximum stress than at higher $\Delta \varepsilon / 2$ (Figure 4 a)) and $\Delta \varepsilon_{p}$ decreases with $44.4 \%$ compared with a cycle at the beginning of the test and a cycle at $90 \%$ of life.

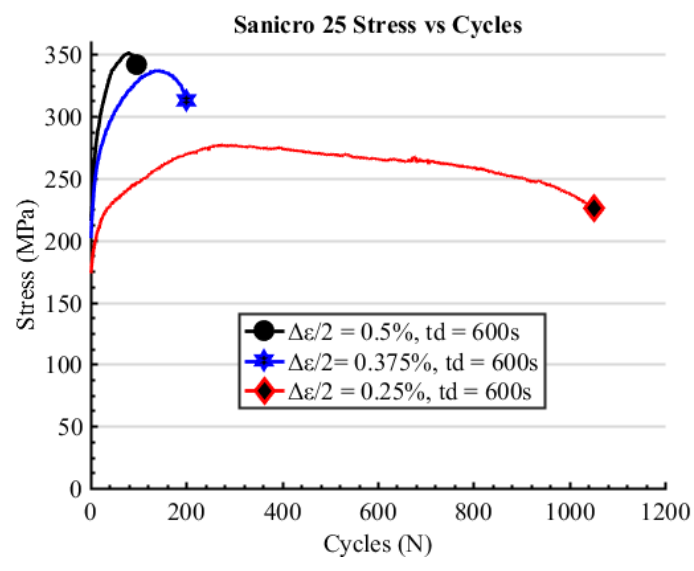


Fig 2. Maximum stress versus cycles to failure curve for Sanicro 25 tests with different strain amplitudes and constant

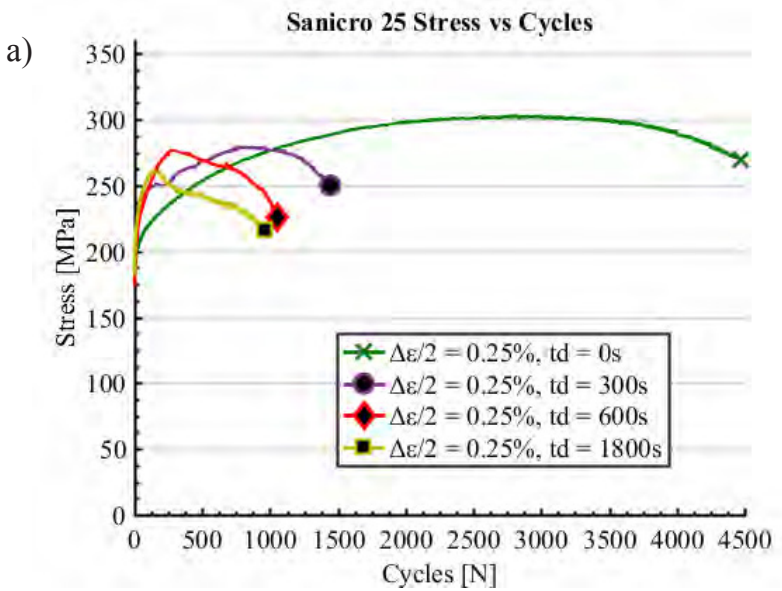

dwell time.

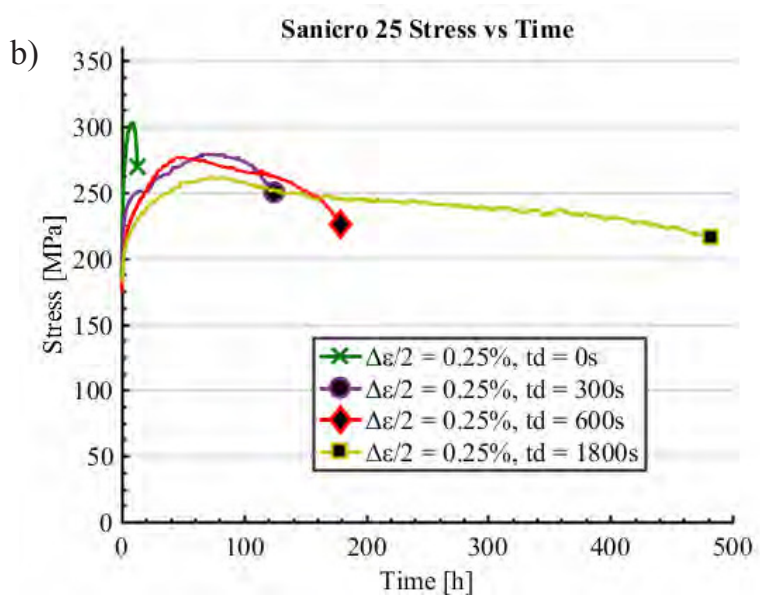

Fig 3. Sanicro 25 test result for tests with different dwell time and constant strain amplitudes, a) Maximum stress versus cycles to failure, b) Maximum stress versus time to failure.
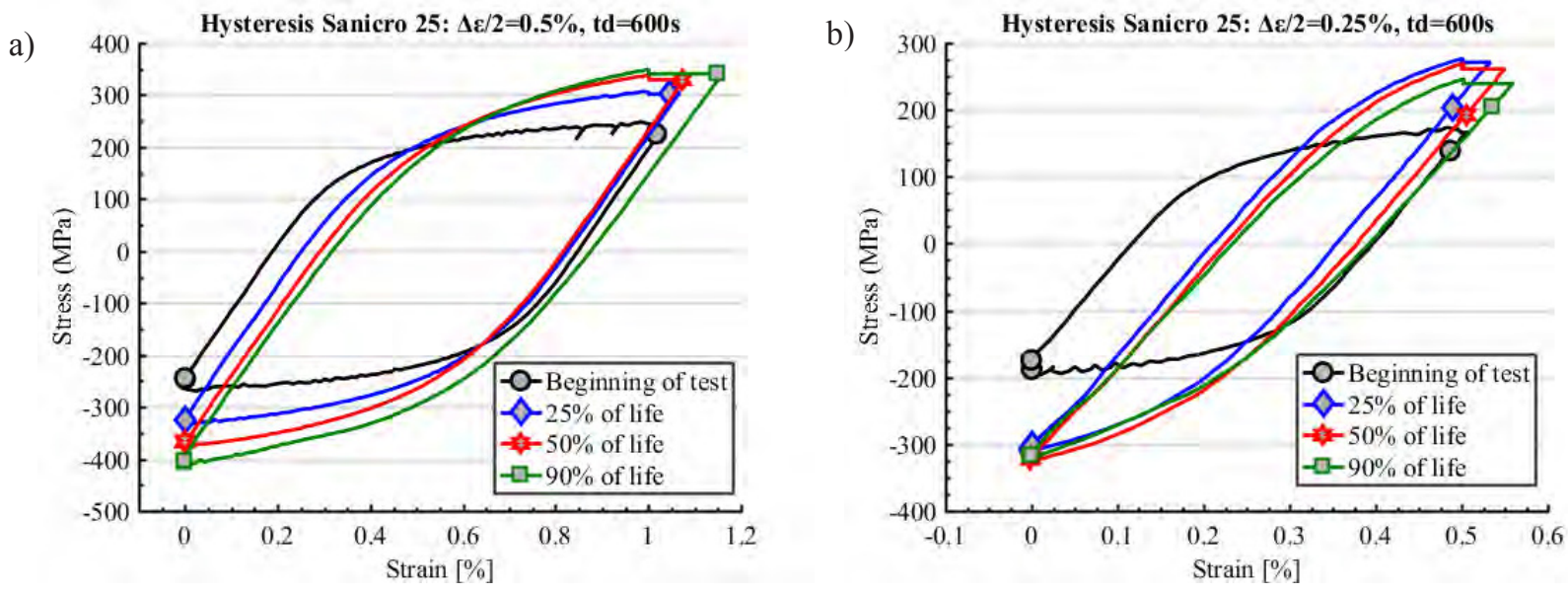

Fig 4. Sanicro 25 hysteresis curves for selected cycles, a) test with higher strain amplitude, b) test with lower strain amplitude.

\subsection{Esshete 1250}

In Figure 5, the mechanical response for Esshete 1250 can be observed. At the initial part of test life, for tests with lower $\Delta \varepsilon / 2(0.25 \%$ and $0.375 \%)$, there are a rapid increase in cyclic hardening and then a cyclic softening after maximum stress. For the test with highest $\Delta \varepsilon / 2$ $(0.5 \%)$ instead of a reduction in hardening after the initial state to a steady-state with constant stress, the response is continuous cyclic hardening before failure. In Figure 6 a), tests with lower $t_{d}(100 \mathrm{~s}$ and 300s) have almost the same mechanical response and creep-fatigue life. This is also the case for tests with medium and long $t_{d}(600 \mathrm{~s}$ and 1800s). However, these similarities are not seen in Figure $6 \mathrm{~b}$ ), were life is calculated in time.

The hysteresis loops in Figure 7 , shows that with higher $\Delta \varepsilon / 2$ (Figure $7 \mathrm{a})$ ), the elongation during $t_{d}$ increases with increasing number of cycles. Comparing a cycle at the beginning with a cycle at $90 \%$ of life, the increase in $\Delta \varepsilon_{p}$ is approximately $56 \%$. In addition, the maximum stress increases from the beginning of the test to $25 \%$ of life, but then stay at the same level until failure. At lower $\Delta \varepsilon / 2$ (Figure $7 \mathrm{~b}$ )) there are first an increase in maximum stress to $25 \%$ of life and then cyclic softening occurs until $90 \%$ of life. The $\Delta \varepsilon_{p}$ increases with increasing numbers of cycles, but the largest increase, $12 \%$, is between a cycle at the beginning of the test to a cycle at $25 \%$ of life, instead of a cycle at $90 \%$ of life.

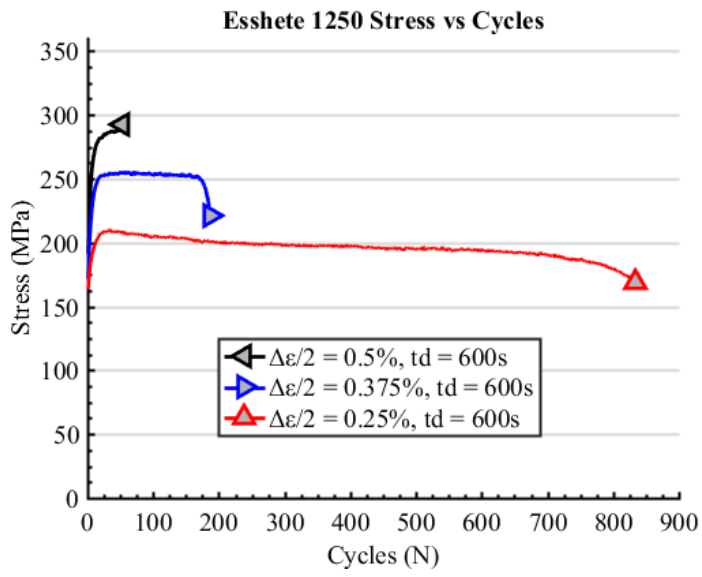

Fig 5. Maximum stress versus cycles to failure curve for 
Esshete 1250 tests with different strain amplitudes and constant

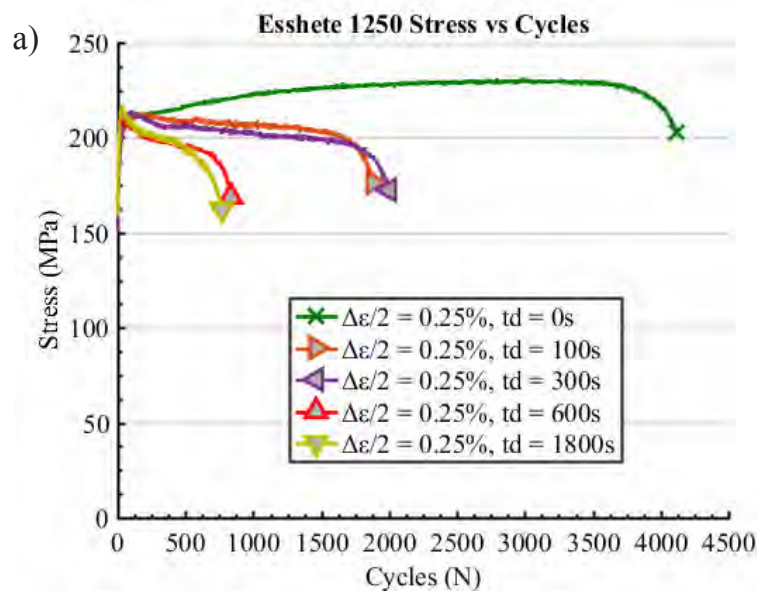

dwell time.

b)

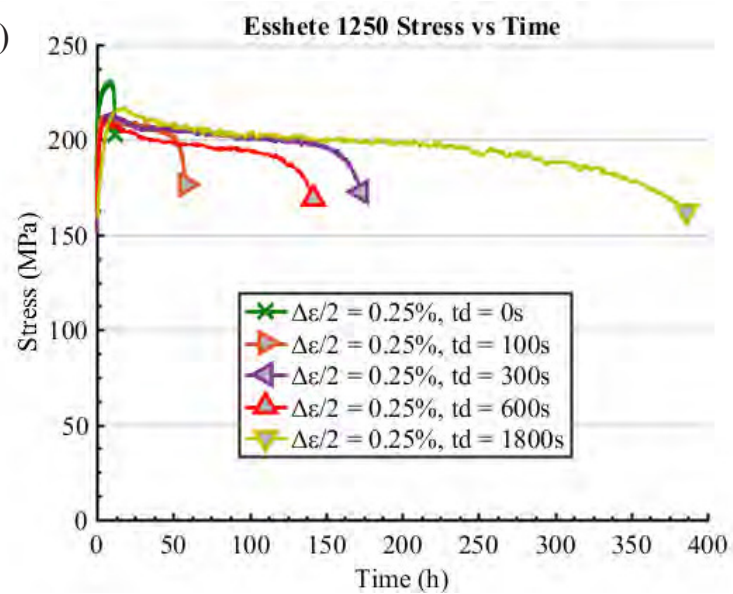

Fig 6. Esshete1250 test result for tests with different dwell time and same strain amplitudes, a) Maximum stress versus cycles to failure, b) Maximum stress versus time to failure.
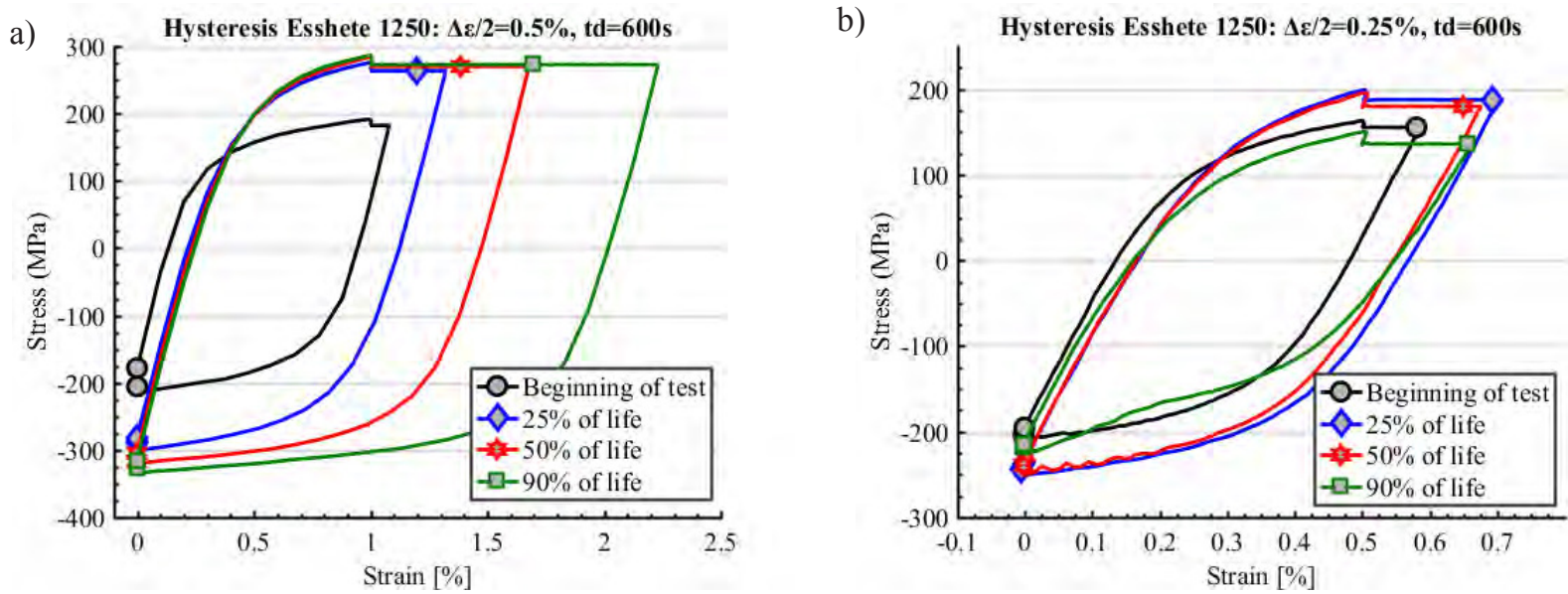

Fig 7. Hysteresis curves for selected cycles, a) test with high strain amplitude, b) test with lower strain amplitude.

\subsection{Creep-fatigue Interaction diagram}

In Figure 8, the linear summation of the creep damage, $D_{c}$, and the fatigue damage, $D_{f}$, are displayed for both Sanicro 25 and Esshete 1250. For Esshete 1250 (Triangular markers) the test with longest $t_{d}(1800 \mathrm{~s})$, is situated (1.01) over the maximum total damage $D=1$ line and the test with $t_{d}=300 \mathrm{~s}$ is close to the $D=1$ line. The other Esshete 1250 tests both exhibits total damage of approximately $D=0.5$.

The Sanicro 25 tests all exhibit more creep damage than fatigue damage. Comparing the two tests with $t_{d}=$ $600 \mathrm{~s}$, the test with higher $\Delta \varepsilon / 2$ showed more creep damage and total damage, $D$, but less amount of fatigue damage. The test with $t_{d}=300$ seconds showed almost equal creep and fatigue damage and the test with longest $t_{d}(1800 \mathrm{~s})$, showed an greater amount of creep damage situated close to the $D=1$ line.

\section{Discussion}

Comparing the different mechanical responses from the Creep-LCF testing of the two investigated austenitic alloys, there are differences in stress levels, $N_{f}, \Delta \varepsilon_{p}$,

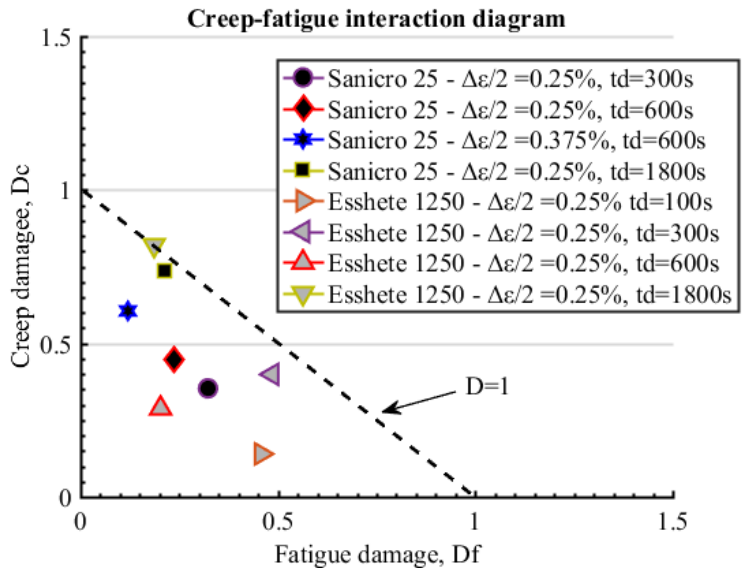

Fig 8. Creep-fatigue interaction diagram for both Sanicro 25 and Esshete 1250.

hardening and softening behaviour. The Sanicro 25 tests all showed increased $N_{f}$ and higher stresses, compared to 
Esshete 1250 tests with the same $\Delta \varepsilon / 2$. This is evident in Figure 9, where stress at half life is plotted against $N_{f}$ using the same dwell time $\left(t_{d}=600 \mathrm{~s}\right)$.

Considering the hardening behaviour of Sanicro 25, it is evident in Figure 3 and 4 that there are a large increase in stress at the beginning of the tests. In addition, there are serrations of the curve at the beginning of the tests, in Figure 4. This is commonly related to dynamic strain aging (DSA) [14, 15]. DSA reduces the dislocation elimination rate and produce point defect concentration because of sufficient movement possibility of interstitial carbon and/or nitrogen atoms or carbon- and/or nitrogen-vacancy pairs or substitutional chromium atom and therefore increases the hardening behaviour which gives higher maximum stresses [14]. In Figure 7, this phenomenon is not seen for Esshete 1250 and is most likely due to the small amount of carbon and chromium content and the absence of nitrogen. This is probably associated with the reduction in $\Delta \varepsilon_{p}$ and the increase of maximum stress for the Sanicro 25 tests and the continuous increase of $\Delta \varepsilon_{p}$ and the stagnation of maximum stress for the Esshete 1250 tests.

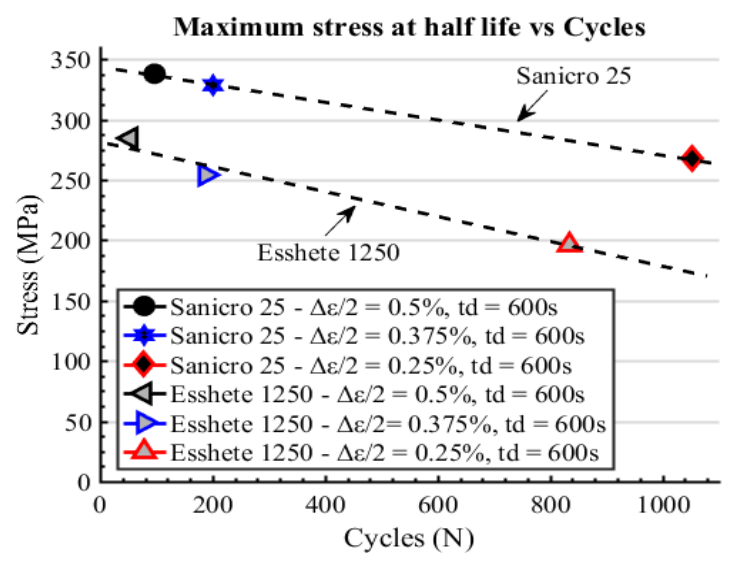

Fig 9. Maximum stress at half cycle life versus cycles to failure for the investigated austenitic alloys.

The tests with different $t_{d}$ and constant $\Delta \varepsilon / 2$ for Esshete 1250 (Figure 6), shows that in general the test with longer $t_{d}$ and therefore more creep, exhibits shorter creep-fatigue life but longer life calculated in time. However, the test with $t_{d}=300$ seconds show both, longer creep-fatigue life compared to the test with $t_{d}=$ 100 seconds and longer life calculated in time compared to the test with $t_{d}=600$ seconds. Consulting the interaction diagram in Figure 8 , this test configuration is close to the maximum total damage $D=1$ line and is therefore not considered to suffer that much from interaction damage and have most likely a competitive damage process (case 2 in Figure 10) [16]. The two test with $t_{d}=100$ seconds and $t_{d}=1800$ seconds lies further at the fatigue part and the creep part of the diagram respectively, which is quite understandable given the difference in cycle configuration. In coherence with Hales and Plumbridge $[9,10]$, the damage interaction behaviour for the test with $t_{d}=100$ seconds should be mostly fatigue dominated even though creep is still active. This should yield transgranular initiation followed by intergranular crack growth in an interactive manner (case 3 in Figure 10), because of the distance to the maximum damage $D=1$ line [16]. The test with $t_{d}=$ 1800 seconds would most likely show both intergranular initiation and growth with some transgranular damage. This in a competitive manner because of the position close to the maximum damage line and therefore lack of interaction damage (case 2 in Figure 10). If the test with $t_{d}=600$ seconds is considered in the interaction diagram, it has a central position with estimated high amount of interaction damage and should exhibit the transgranular crack damage from fatigue to grow into a intergranular progression caused by an additive process between fatigue and creep (case 3 in Figure 10). This interactive damage behaviour could also be contributed from internal triple point wedge cracks, grain boundary voids and initiations from matrix pore or inclusion according to [10].
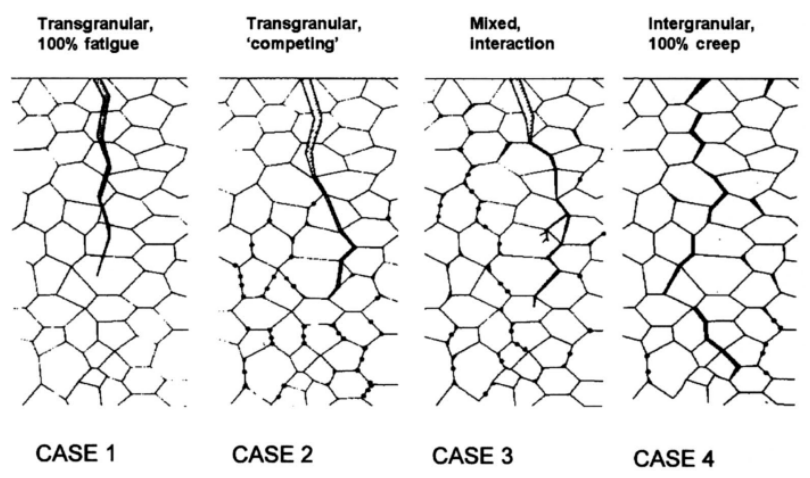

Fig 10. Different cases for creep-fatigue interaction damage, according to Hales [9] (Courtesy of publisher).

From findings of Hales [9], creep damage is more prominent at higher strain ranges. This coincides with the results in Figure 8, from Sanicro 25 test configurations with the same amount of dwell time $\left(t_{d}=\right.$ $600 \mathrm{~s}$ ) but different strain amplitudes i.e. the test with $\Delta \varepsilon / 2=0.375 \%$ and the test with $\Delta \varepsilon / 2=0.25 \%$. In the figure, the test with the higher $\Delta \varepsilon / 2(0.375 \%)$ exhibits a dominant part of creep damage and also less effect of interaction damage because of the position closer to the maximum interaction damage line compare to test 4 . Further more, the test with lower $\Delta \varepsilon / 2(0.25 \%)$ show less interaction damage compared to the Esshete 1250 test with identical test configuration which could be contributed by slightly more dominant creep damage process.

If the creep damage fraction is high $\left(D_{c} \geq 0.7\right)$ in the Creep-fatigue interaction diagram (Figure 8) the interaction damage part becomes almost non-existent, for the two investigated austenitic alloys and the damage initiation mechanism should be close to case four in Figure 10, with intergranular growing cracks. When the tests with the highest amount of creep damage $\left(t_{d}=\right.$ 1800 s) is compared for the alloys, the Esshete 1250 test has higher fraction of creep damage, even though it experience lower maximum stress and yield less amount of $N_{f}$. In this case, it is therefore reasonable to establish that Sanicro 25 has superior creep strength to Esshete 
1250 and that it enhances the creep-fatigue life. According to Guocai et.al [13], the high creep strength at elevated temperatures for Sanicro 25 is because of interaction of dislocation and precipitates acts as pinning points for dislocation movement. Also nano-sized particles like $\mathrm{M}_{23} \mathrm{C}_{6}$ and Laves phase and smaller nanoprecipitates such as copper rich- and MX particles were found to impede dislocation movement [13].

If the creep damage fraction is lower $\left(D_{c} \leq 0.7\right)$, in the Creep-fatigue interaction diagram (Figure 8), the interaction damage influences the creep-fatigue life more and it is harder to predict the amount of interaction damage for a specific test cycle configuration. This is evident if the Esshete 1250 tests with $D_{c} \leq 0.7$ is considered in Figure 8. For Sanicro 25 tests, the interaction damage seems to stay close to $30 \%$ independent of the cycle configuration, but more tests and with different configurations need to be analysed before a general design trend can be established.

The obtained mechanical data from this study has been analysed using Hales and Plumbridges work $[9,10]$ to predict and estimate the type of initiation damage from creep-fatigue interaction behaviour. However, a microstructural investigation for the different tested specimens from this study should be conducted before a more comprehensive analysis and understanding of the damage mechanisms can be obtained.

\section{Conclusions}

The creep-fatigue interaction study for the two austenitic alloys contributed results, analysis of the mechanical response and estimated damage initiation mechanisms. From the discussed results, these conclusions are deduced:

- Sanicro 25 suffered higher maximum stresses but still shows superior creep-fatigue cycle life compared to Esshete 1250.

- Compared with Sanicro 25, Esshete 1250 shows more creep elongation for the same amount of strain amplitude and dwell times.

- Both alloys shows creep-fatigue interaction damage for most test configurations.

\section{Acknowledgements}

Present study was financially supported by AB Sandvik Materials Technology in Sweden and the Swedish Energy Agency through the Research Consortium of Materials Technology for Thermal Energy Processes, Grant No. KME-701. AFM Strategic Faculty Grant SFO-MAT-LiU\#2009-00971 at Linköping University is also acknowledged.

\section{References}

[1] U.S. Department of Energy, "International Energy Outlook 2005," (2005).

[2] L. Trygg and S. Amir, "European perspective on absorption cooling in a combined heat and power system- A case study of energy utility and industries in Sweden," Appl. Energy, vol. 84, no. 1319, (2007).

[3] R. Saidur, E. A. Abdelaziz, A. Demirbas, M. S. Hossain, and S. Mekhilef, "A review on biomass as a fuel for boilers," Renew. Sustain. Energy Rev., vol. 15, no. 5, pp. 2262-2289, Jun. (2011).

[4] A. G. Tumanovskii et al., "Review of the coal-fired, over-supercritical and ultra-supercritical steam power plants," Therm. Eng., vol. 64, no. 2, pp. 83-96, Feb. (2017).

[5] J. YIN and Z. WU, "Corrosion Behavior of TP316L of Superheater in Biomass Boiler with Simulated Atmosphere and Deposit," Chinese J. Chem. Eng., vol. 17, no. 5, pp. 849-853, (2009).

[6] R. Blum and R. Vanstone, "Materials Development for Boilers and Steam Turbines Operating At $700^{\circ}$ C," Proc. 6th Int. Charles Parsons Turbine Conf. Dublin, Irel., pp. 498-510, (2003).

[7] Eurelectric, "Flexible generation: Backing up renewables," Eurelectric, Brussels, (2011).

[8] K. Dietrich, J. M. Latorre, L. Olmos, and A. Ramos, "The Role of Flexible Demands in Smart Energy Systems," in Energy System, pp. 79-97, (2013).

[9] R. Hales, “A Quantitative Metallographic Assessment of Structural Degradation of Type 316 Stainless Steel During Creep-Fatigue," Fatigue Fract. Eng. Mater. Struct., vol. 3, no. 4, pp. 339-356, (Oct. 1980).

[10] W. J. Plumbridge, "Uprating and life assessment under fatigue-creep conditions," Int. J. Press. Vessel. Pip., vol. 59, no. 1-3, pp. 119-129, (Jan. 1994).

[11] ASTM, “Creep-Fatigue Testing," E2714 - 13. ASTM International, pp. 1-15, (2014).

[12] R. Jetter, "Subsection NH-Class 1 Components in Elevated Temperature Service," in Companion Guide to the ASME Boiler and Pressure Vessel Code, Volume 1, Third Edition, Three Park Avenue New York, NY 10016-5990: ASME, pp. 409-445, (2007).

[13] G. Chai, M. Boström, M. Olaison, and U. Forsberg, "Creep and LCF Behaviors of Newly Developed Advanced Heat Resistant Austenitic Stainless Steel for A-USC," Procedia Eng., vol. 55, no. 55, pp. 232-239, (2013).

[14] L. H. De Almeida, I. Le May, and P. R. O. Emygdio, "Mechanistic modeling of dynamic strain aging in austenitic stainless steels," Mater. Charact., vol. 41, pp. 137-150, (1998).

[15] G. Chai, "Damage Mechanism of Low Cycle Fatigue in an Advanced Heat Resistant Austenitic Stainless Steel at High Temperature," Procedia Mater. Sci., vol. 3, pp. 1754-1759, (2014).

[16] R. P. Skelton and D. Gandy, "Creep - fatigue damage accumulation and interaction diagram based on metallographic interpretation of mechanisms," Mater. High Temp., vol. 25, no. 1, pp. 27-54, (Mar. 2008). 